\title{
Ramped position, an uncertain future
}

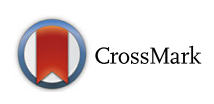

\author{
Luigi Vetrugno, Daniele Orso ${ }^{*}$ (iD and Tiziana Bove
}

See related research by Cabrini et al., https://ccforum.biomedcentral.com/articles/10.1186/s13054-017-1927-3

We have carried out a detailed reading of the article by Cabrini et al., "Tracheal intubation in critically ill patients: a comprehensive systematic review of randomized trials" [1], in which the authors conducted a comprehensive review of the effects of orotracheal intubation in critically ill patients. The article provides the most upto-date, complete review on this topic. Evidence of the usefulness of pre-oxygenation is incontrovertible. However, we disagree with the authors' conclusions regarding the ramped position. Specifically, we believe that the statement "the effect of the ramped position [results] in increasing the number of intubation attempts" is not sufficiently evidence based. Cabrini et al. refer to a single study $-\mathrm{a}$ randomized controlled trial by Semler et al. [2]-in which randomly selected ICU patients were intubated either in the sniffing position or in the ramped position. The primary outcome of this study was the improvement of the lowest saturation between the two groups. The authors did not highlight a statistically significant difference. Secondary outcomes were the grade of glottic view, the difficulty of intubation, and the number of intubation attempts. The authors observed worse results for these outcomes in the ramped position group. Xue et al. [3], however, have raised some questions about the reliability of this study. We would also like to point out that the conclusion reached by Cabrini et al. in their systematic review referred to a secondary outcome of the trial by Semler et al. The statistical power of the latter was calculated to respond to the primary end-point. However, the sample size was not adequate to respond incontrovertibly to the secondary outcomes. As secondary outcomes, the obtained results regarding the difficulty of intubation and the number of attempts can only be taken as hypothesis generators [4]. We believe, therefore, that the conclusion regarding the ramped position reported by Cabrini et al. is not sufficiently evidence based, and that questions remain as to its validity.

\section{Authors' response}

\section{Luca Cabrini, Giovanni Landoni, Alberto Zangrillo, Massimo Antonelli, Rinaldo Bellomo and Paolo Pelosi}

We are grateful to Vetrugno and co-workers for their careful reading of our article [1]. Their letter gives us the opportunity to further underline the two most relevant characteristics of our study.

First of all, we fully agree with the comments made by Vetrugno et al. on Semler's randomized trial [2]: the evidence in favor of the sniffing position compared to the ramped position is weak, derived from secondary outcomes, and limited to the number of intubation attempts and quality of glottis view, while other outcomes showed no difference. On the other hand, the study was relatively large and multi-center, so increasing its reliability. We were very cautious in our conclusions, stating that "The sniffing position might be the position of choice for

\footnotetext{
* Correspondence: sd7782.do@gmail.com

Anesthesiology and Intensive Care Clinic, Department of Medicine, University of Udine, 33100, P.le S. Maria della Misericordia 15, Udine, Italy
}

laryngoscopy." Further research is clearly required before a strong recommendation can be made, and again (in line with Vetrugno's et al. letter) we stated that "Our findings ... will inform future research." This was a main purpose of our study.

Second, we would underline that the results by Semler et al. are in contrast with previous studies performed in the operative theatre in elective patients [5-7]. This supports the assumption at the basis of our study that intubation of critically ill patients can be quite different from intubation of elective surgical patients in the operating theatre. Until new studies are published, the weak evidence from Semler et al.'s study is the best available evidence for critically ill patients.

In conclusion, in accordance with Vetrugno et al. we hope that in the near future more data will be made available to improve the effectiveness and safety of tracheal intubation in the critical care scenario. 


\section{Authors' contributions}

LV participated in the design of the study. DO participated in the design of the study and helped to draft the manuscript. TB participated in the design of the study and coordination. All authors read and approved the final manuscript.

\section{Competing interests}

The authors declare that they have no competing interest.

\section{Publisher's Note}

Springer Nature remains neutral with regard to jurisdictional claims in published maps and institutional affiliations.

Received: 14 March 2018 Accepted: 17 April 2018

Published online: 13 May 2018

\section{References}

1. Cabrini L, Landoni G, Baiardo Radaelli M, et al. Tracheal intubation in critically ill patients: a comprehensive systematic review of randomized trials. Crit Care. 2018;22:6

2. Semler MW, Janz DR, Russell DW, et al. A multicenter, randomized trial of ramped position vs sniffing position during endotracheal intubation of critically ill adults. Chest. 2017;152:712-22.

3. Xue FS, Li HX, Liu YY. Comparing ramped position vs sniffing position for intubation: study design is crucial. Chest. 2017;152:1091-2.

4. Vetter TR, Mascha EJ. Defining the primary outcomes and justifying secondary outcomes of a study: usually, the fewer, the better. Anesth Analg. 2017:125:678-81.

5. Lee BJ, Kang JM, Kim DO. Laryngeal exposure during laryngoscopy is better in the 25 degrees back-up position than in the supine position. $\mathrm{Br} \mathrm{J}$ Anaesth. 2007:99:581-6.

6. Cattano D, Melnikov V, Khalil Y, Sridhar S, Hagberg CA. An evaluation of the rapid airway management positioner in obese patients undergoing gastric bypass or laparoscopic gastric banding surgery. Obes Surg. 2010;20:1436-41.

7. Lebowitz PW, Shay H, Straker T, Rubin D, Bodner S. Shoulder and head elevation improves laryngoscopic view for tracheal intubation in nonobese as well as obese individuals. J Clin Anesth. 2012:24:104-8. 